\title{
Development of Fish Descaling Machine
}

\author{
K. Venkat Reddy ${ }^{*}$, N. Uday Kumar ${ }^{2}$, K. Sada Siva Rao ${ }^{3}$, S. Hiregoudar ${ }^{2}$, \\ A. C. Sudhakar ${ }^{2}$, Devanand Maski ${ }^{2}$ and K. T. Ramachandra ${ }^{2}$ \\ ${ }^{1}$ College of Agricultural Engineering, Kandi, Sangareddy, India \\ ${ }^{2}$ University of Agricultural Sciences (UAS), Raichur, India \\ ${ }^{3}$ PJTS Agricultural University, Rajendranagar, India \\ *Corresponding author
}

Keywords

Rohu, Fish descaling machine, Post harvest

Processing of fish

Article Info

Accepted:

17 November 2019

Available Online:

10 December 2019

\section{A B S T R A C T}

India is one of the leading fish producing countries in the world both in inland fisheries and marine fisheries. Fish food forms an important component of nutritional diet of many Indians. Indian fisheries is contributing significantly to the economy of the country, occupying around $0.91 \%$ of the GDP. In spite of its importance and support to more than 14 million people directly or indirectly, the industry is lacking good indigenous machinery for post harvest operations. People are using age old practices for descaling, cleaning and other operations. Present $\mathrm{PhD}$ work has been taken up to develop a semi-continuous descaling machine indigenously to cater to the inland fish processing. The machine has been developed at College of Agricultural Engineering, Kandi, Sangareddy, Telangana State. The machine istrial tested for its capacity and efficiency of descaling using different speeds of operation for Rohu fish.

\section{Introduction}

India occupies the third position in fisheries and second position in aquaculture in the world. Total fish production in India was 12.60 million tonnes $(\mathrm{mt})$ and the country exported $1.38 \mathrm{mt}$ fish and fish products with a value of over ₹ 45,000 crore in 2017-18. Inland fisheries is contributing around $65 \%$ and about $50 \%$ of the total production is from culture fisheries, and constitutes about $6.3 \%$ of the global fish production (http://nfdb.gov.in, 2019).

More than 50 different types of fish and shellfish products are being exported to 75 countries around the world. Fish and fish products have presently emerged as the largest group in agricultural exports from India. This accounts for around $10 \%$ of the total exports 
and nearly $20 \%$ of the agricultural exports, and contribute to about $0.91 \%$ of the GDP and $5.23 \%$ to the Ag - GVA of the country. This sector is providing employment to more than 14 million people (http://nfdb.gov.in, 2019).

\section{Post harvest processing operations of fish}

The post harvest processing of fish consists of evisceration, beheading, scaling, cutting of fins and belly flaps, slicing of whole fish into small parts or steaks and other operations based on the consumption like filleting, skinning, grinding of skinned fillets etc. These pre-processed products are sold or further processed to obtain value added products (FAO, 2016).

Fish descaling is one of the important preliminary operations in fish processing. Descaling is the process of removal of scales on the fish skin. Many fresh water fish like rohu (Labeo rohita) need descaling and the fish vendors remove the scales manually using hand tools. They use different kinds of brushes or knives to remove the scales. Most of the inland catch fish sale happens near the catchment areas or near public places like vegetable markets, by the side of road junctions in the urban areas. In spite of fisheries' vast potential in terms of nutritional, economical and employment value, fish descaling is done in an improper and crude method creating an unhygienic environment leading to severe health hazards. Manual scaling of fish is a laborious and tedious process involving lot of drudgery. It may sometimes cause bruising of fingers and palms of the workers leading to infections, diseases and lost revenue to the vendors.

Saizon (1978) invented a hand-held electrically operated fish scaler and obtained a patent (US4107819A). Damp (1989) invented a portable fish scaler and obtained a patent. Khandani (2005) described the best practices in mechanical design of machines and developing prototypes. Gaikwad et al., (2013) developed a hand-held electrical fish descaling machine in CIPHET, Ludhiana and it is in the process of commercialization. Ghaly et al., (2013) reviewed fish beheading process.

Kanna et al., (2013) developed an automatic fish scaling machine that consists of knurled rollers and blade rollers which are fixed and rotate on its own axis. Supporting rollers are provided with compression spring of very less stiffness in order to adjust according to the shape of the fish and to provide required pressure to hold. Since fish shape is convex, the blades are designed in concave structure. A conveyor is placed between the rollers which carries the fish. The rotation of knurled rollers and blade rollers are opposite to the fish scales. The supporting roller pushes the fish towards these rollers. Hence, action results in complete removal of fish scales.

Nahak (2015) designed a fish scaling device. Based on the various existing models and morphological analysis, selected drum fish scaler for further development. The design was an adaptation of an existing model of Open Country Campware's Tumble Drum Fish Scaler and simulated in CATIA V5R21.

Anonymous (2016) manufactured a fish descaling machine for haddock and similar fish with through put rate of 25-50 fishes per min, working range of $1-8 \mathrm{~kg}$, fish thickness as $\max 95 \mathrm{~mm}$, fish height $\max 200 \mathrm{~mm}$, water consumption at $12.5 \mathrm{l} / \mathrm{min}$ at 2 bar and $201 / \mathrm{min}$ at 5 bar.

This is a high speed descaling machine equipped with four descaling spindles, two above and two below the fish, with different geometries, to descale high and narrow fish. The speed through the machine is adjustable by one button without steps. 
FAO (2016) found that most of the fresh water fish are descaled. Fish intended for filleting, smoking or deboning is not scaled. Tools are moved over the body of fish from tail fin towards the head, removing the scales. It was reported that electrical hand held scaler simplifies and speed up the scaling process. They are used as secondary scalers in large processing units after descaling using automated machines. This scaler consists of a cylindrical rotating scraper of $30-40 \mathrm{~mm}$ diameter powered by an electric motor and connected to it with a flexible rod.

A cylindrical rotating scaler rotating on a horizontal axis removes the scales in 2 to 7 minutes depending upon the species and size of the fish as well as type of the slits on the surface of the drum and the rotational speed.

Most of the descalers are designed on the same principal. Another model, a vertical cylindrical scaler, with rotating bottom and a fixed side wall is widely used in small scale fish processing plants. Fish $(30-40 \mathrm{~kg})$ are loaded from the top and unloaded through the door in the side wall. Scales catch on small contoured slits cut in the bottom and side wall of the device, and are thus pulled out of the skin. Sometimes, cement mixers are used by replacing the drum with stainless steel drum.

Currently, many of the different types of fish descaling machines available are designed and manufactured outside the country. There are different types of power assisted, hand-held or drum type scalers for house hold purpose or for small vendors. Large mechanized and automatic descalers are available for commercial fish processing establishments. Their usage is not widespread among local fish vendors. This could be because of the lack of locally made machines that suit their needs or higher cost of imports or inconvenience in operation. There are no or limited number of commercial scale machines being used by small scale vendors currently in the market. Looking at the existing gap, need is felt for developing fish descaling machine indigenously for the local needs that suit the requirement of small fish vendors, restaurants etc. The new machine shall be able to operate in a semi continuous manner to make the descaling operation easy, less drudgery, and collect the scales to be disposed off safely.

\section{Methodology for development of descaling machine}

\section{Selection of fish}

Locally consumed, Rohu fish (Labeo rohita) of uniform size is selected from the market for trail testing of the developed machine.

\section{Proposed equipment}

Fish descaling machine

\section{Technical details of the design}

The machine mainly consists of

Descaling roller assembly

Electric motor assembly

Shaper bracket mount assembly

Supporting frame assembly

The fish descaling machine has been developed based on the principle of subjecting the scales of the fish to shearing action from the rollers on which teeth are cut longitudinally on the surface. Blades are spring mounted on a shaper bracket assembly to hold the fish tightly against the rotating rollers while the rollers clear the scales of the fish. The rollers are fixed on shafts with keys. Two rollers rotate in an anti-clock wise direction while all other rollers are moving in a clockwise direction. 
A supporting frame assembly $1.0 \mathrm{~m}$ length, $0.62 \mathrm{~m}$ width and $0.71 \mathrm{~m}$ height made of MS tubes is fabricated to support the descaling machine. A bottom plate assembly is fixed to the frame by welding. This plate assembly consists of side plates, opening and closing ports for entry of the raw fish and exit of the descaled fish respectively. The back plate has 11 holes for placing the shafts. A bearing block with 11, $25 \mathrm{~mm}$ dia holes drilled using Zig boring machine, to mount the shafts using bearings and bush supports. Shafts are mounted on the bearing block and back plate. Chain sprockets are positioned at the backside of the shafts to drive the roller assembly to descale and guide the fish along the rollers. Descaling rollers are fixed on the front side of the shafts using keys. Chain is mounted on the sprockets, and is connected to a $1 \mathrm{hp}$ motor which is run through a variable frequency drive to control the speed of operation.

Shaper bracket mount assembly consists of shaper plates fixed to square rods. This assembly is positioned using bushes on a supporting angle bracket frame mounted over the roller assembly. The shaper plates are held at an angle on the rollers with the help of springs fixed to the angle frame. The height of the angle frame assembly is adjusted based on the size of the fish to be scaled. Rollers are 45 $\mathrm{mm}$ in diameter on which teeth are cut for giving shearing action on fish scales. One master roller with larger size is placed to scrape off the side scales effectively. Front cover is provided to protect the operator from any untoward incident during the operation. Water is sprayed on to the descaling fish to wash off the scales continuously. All the fish contact materials are made up of stainless steel and other parts are made of MS material. During the descaling operation, fish is fed from the entry port and moves towards the exit port while the rollers scalp the scales while the fish is moving over them.

\section{Results and Discussion}

Trials were conducted to know the functionality of the descaling machine. Rohu fish with following specifications was selected for the testing.

Average length of the fish: $0.27 \mathrm{~m}$

Average width of the fish: $0.01 \mathrm{~m}$

Average weight of the fish: $0.644 \mathrm{~kg}$

Linear speed of the roller: $0.6 \mathrm{~ms}^{-1}$

Table.1 Specifications of the machine

\begin{tabular}{|c|c|c|}
\hline Sl. No. & Description & Value \\
\hline $\mathbf{1}$ & Length of the machine & $1.0 \mathrm{~m}$ \\
\hline $\mathbf{2}$ & Width of the machine & $0.62 \mathrm{~m}$ \\
\hline $\mathbf{3}$ & Height of the machine & $1.0 \mathrm{~m}$ \\
\hline $\mathbf{4}$ & Size of the motor used & $1 \mathrm{hp}$ \\
\hline $\mathbf{5}$ & Diameter of the roller & $45 \mathrm{~mm}$ \\
\hline $\mathbf{6}$ & Length of the roller & $124 \mathrm{~mm}$ \\
\hline
\end{tabular}


Fig.1 Shaper bracket mount drawing

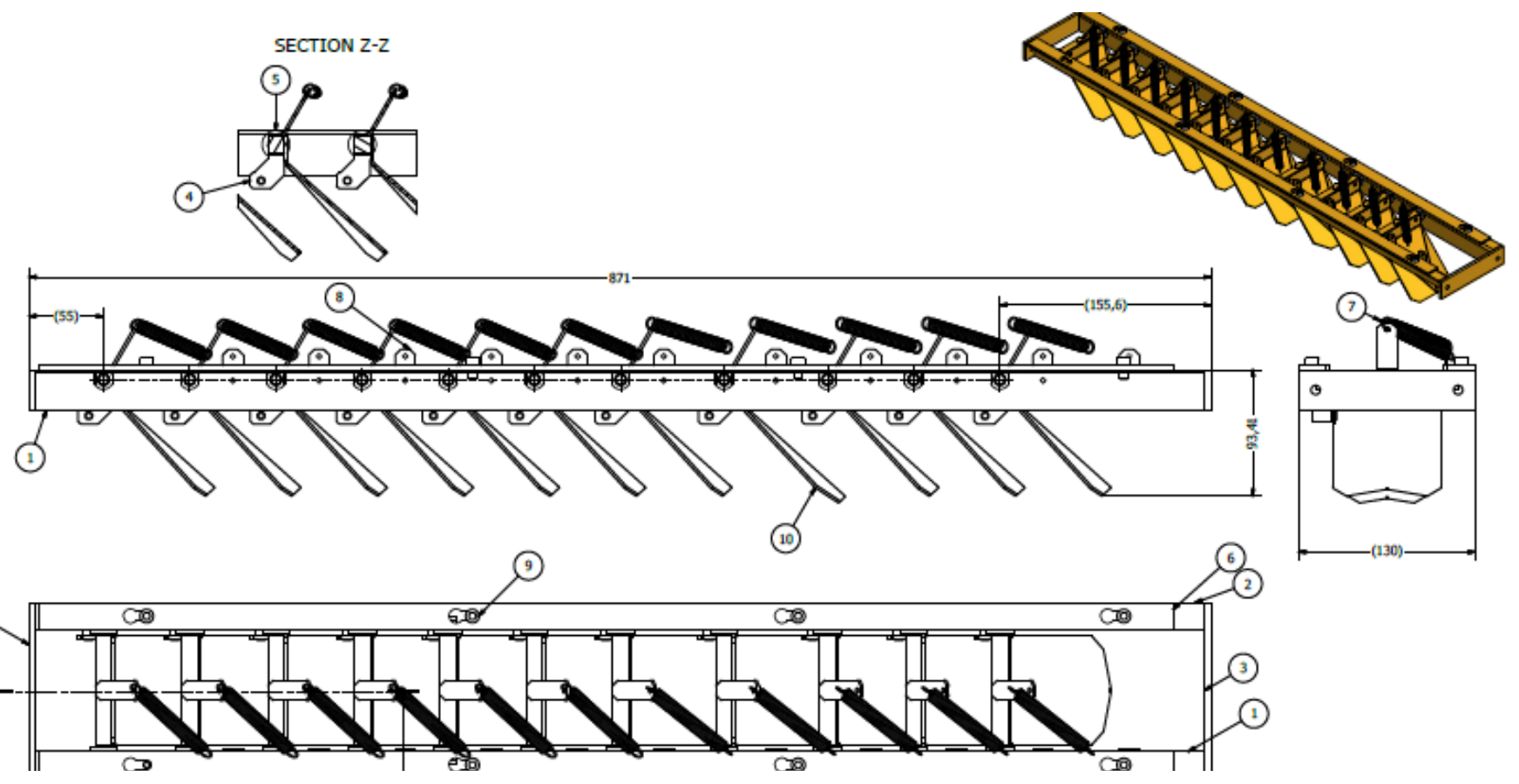

\begin{tabular}{|c|c|l|l}
\hline \multicolumn{5}{|c}{ PARTS LIST } \\
\hline ITEM & QTY & \multicolumn{1}{|c}{ PART NUMBER } & \multicolumn{1}{c}{ DESCRIPTION } \\
\hline 1 & 1 & FSR20023 & BRCKET PLATE \\
\hline 2 & 1 & FSR20024 & BRCKET PLATE \\
\hline 3 & 2 & FSR20025 & BRCKET PLATE \\
\hline 4 & 10 & FSR20020 & SHAPER BRACKET \\
\hline 5 & 22 & FSR20022 & BUSH \\
\hline 6 & 2 & FSR20027 & LOCKING PLATE \\
\hline 7 & 11 & FSR20044 & Extension Service Springs \\
\hline 8 & 11 & FSR20045 & SPRING PLATE \\
\hline 9 & 8 & JIS B 1176 - M6 x 10 & Cylinder Head Cap Screw \\
\hline 10 & 1 & FSR20051 & SHAPER BRACKET
\end{tabular}


Fig.2 Assembly of rollers and shaper bracket with shaper plates

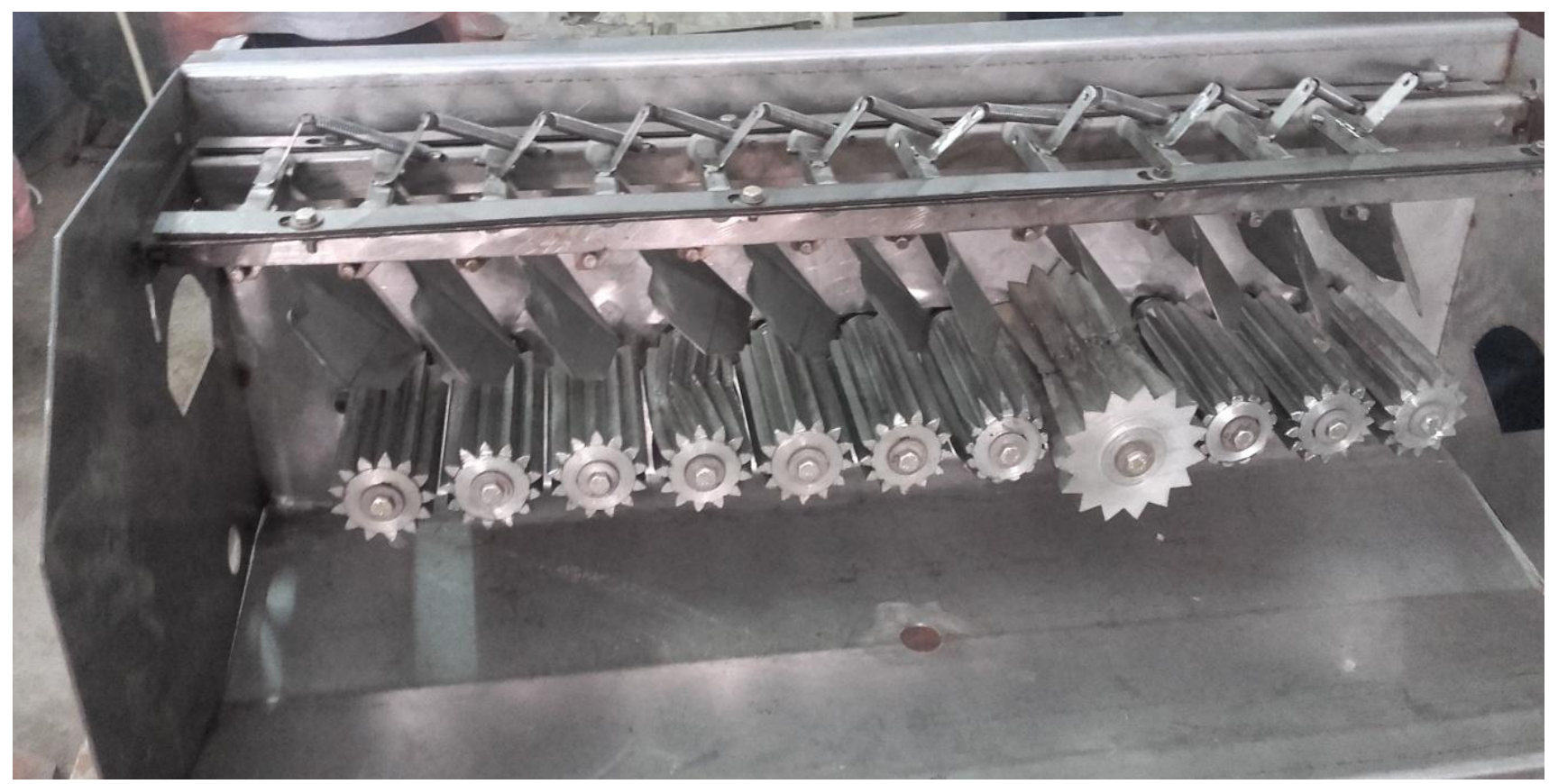

It was required to run the descaling operation twice for each side of the fish to remove the scales. During the trial tests, following parameters were observed and recorded. Fish descaling percentage or efficiency observed was about 55\% during first pass and 15\% during the second pass, obtaining $70 \%$ overall efficiency. Depending upon the speed of the machine in a continuous operation, with intermittent intervals of 5 seconds for loading the fish in each pass, number of fish that can be descaled was found out for 15 minutes. It was observed that approximately $5.8 \mathrm{~kg}$ fish or 9 fish (each weighing about $0.644 \mathrm{~kg}$ ) could be descaled in 15 minutes (Fig. 1 and 2; Table 1).

Fish descaling machine developed has a capacity of about $23 \mathrm{~kg}$ per hour with an overall efficiency of about $70 \%$. It was felt that the capacity of the machine was satisfactory whereas, the efficiency needed improvement. It is observed that different shearing surfaces and shaper plate sizes \& shapes can be experimented to improve the efficiency.

\section{References}

Anonymous, 2016, Baader Island ehf, Ice land, Descaling machine for Haddok and similar fish.

Bhandari, V. B., 2010, Design of machine elements. Tata McGraw-Hill Publishing Company, Third Edition, New Delhi.

Damp, J. B., 1989, Fish scaling apparatus, US Patent number US 4839942 A, $20^{\text {th }}$ June, 1989.

FAO, 2016, Preliminary processing of fresh water fish, fresh water fish processing and equipment in small firms, $F A O$ Corporate Document Repository, Fisheries and Aquaculture Department, FAO, Rome 3: 3-12.

Gaikwad, N., Ahmed, T., and Singh, A., 2013, Design, development and performance evaluation of fish descaling machine, Researchgate, Conference Paper.

Ghaly, A. E., Ramakrishnan, V. V., Brooks, M. S., Budge, S. M. and Dave, D., 2013, Fish processing wastes as a potential source of proteins, amino 
acids and oils: A critical review, $J$. Microb. Biochem. Technol., 5(4): 107129.

Kanna, M. R., Mathan, C., Krishnamoorthy, M. V., Mithilesh, M. and Kanna, P. R., 2013, Velammal College of Engineering, Madurai, http://gyti. techpedia.in/project-detail/automatic-

fish-scaling-machine/1011, $25^{\text {th }}$ Revised Edition.

Khandani, S., 2005, Education Transfer Plan, Engineering Design Process, http://www.iisme.org/ETPExemplary.c $\mathrm{fm}$

Mendelsohn, J. M. and Callan, J. G., 1980, Evaluation of a prototype fish cleaning machine with proposals for a commercial processing line, Marine Fisheries Review, January: 38-43.

Nahak, N., 2015, B.Tech. Thesis, Mechanical engineering department, NIT, Rourkela: 11-23.

NFDB, 2019, Department of Fisheris, Ministry of Fisheries, Animal Husbandry, and Dairying, Government of India, New Delhi. http://nfdb.gov.in/about-indianfisheries.htm.

Saizon, S. F., 1978, Handheld electrically operated fish scaler, US Patent number US 4107819 A, Aug. $22^{\text {nd }} 1978$.

\section{How to cite this article:}

Venkat Reddy, K., N. Uday Kumar, K. Sada Siva Rao, S. Hiregoudar, A. C. Sudhakar, Devanand Maski and Ramachandra, K. T. 2019. Development of Fish Descaling Machine. Int.J.Curr.Microbiol.App.Sci. 8(12): 2434-2440. doi: https://doi.org/10.20546/ijcmas.2019.812.286 